\title{
EL PRODUCTO PANEUROPEO DE PENSIONES INDIVIDUALES (PEPP) COMO UNA EXPERIENCIA REGULATORIA INTERESANTE PARA IBEROAMÉRICA
}

\author{
THE PAN-EUROPEAN PERSONAL PENSION \\ PRODUCT (PEPP) AS AN INTERESTING REGULATORY \\ EXPERIENCE FOR IBEROAMERICA
}

\author{
ALBERTO J. TAPIA HERMIDA* \\ Fecha de recepción: 8 de noviembre de 2019 \\ Fecha de aceptación 1 diciembre de 2019 \\ Disponible en línea: 30 de diciembre de 2019
}

Para citar este artículo/To cite this article

Tapia Hermida, Alberto J., El producto paneuropeo de pensiones individuales (PEPP) como una experiencia regulatoria interesante para Iberoamérica, 51 Rev.Ibero-Latinoam.Seguros, 15-34 (2019). https://doi.org/10.11144/Javeriana.ris51.eppp

doi:10.11144/Javeriana.ris51.eppp

Licenciado en Derecho por la Universidad Autónoma de Madrid. Doctor en Derecho por la Universidad Complutense de Madrid. Es Abogado de ESTUDIO JURÍDICO SÁNCHEZ CALERO. Ha sido Letrado de la Comisión Nacional del Mercado de Valores. Es experto en Derecho de seguros y ha intervenido en numerosos litigios relativos a este sector. También tiene una dilatada experiencia en mercados financieros y en Derecho bancario y bursátil. Emite dictámenes e informes en asuntos mercantiles y ha sido requerido para actuar como experto en procedimientos judiciales y arbitrales. Catedrático Acreditado de Derecho mercantil. Facultad de Derecho. Universidad Complutense de Madrid. Contacto: atapia@sanchezcalero.com 


\section{RESUMEN}

En este estudio se analiza el Reglamento (UE) 2019/1238 que establece el producto paneuropeo de pensiones individuales (PEPP) en tres apartados: En primer lugar, se exponen los aspectos generales referidos a su forma, su contenido y su aplicación temporal. En el segundo apartado, se examina la estructura del PEPP integrada por sus aspectos objetivos y por los sujetos que intervienen en su desarrollo. El tercer apartado se dedica a analizar el funcionamiento del PEPP desde dos puntos de vista: primero, según las actuaciones previstas (inscripción, distribución y supervisión); y, segundo, según las fases del desarrollo de estos PEPP que son dos: la primera fase es la de acumulación y en ella se regulan las normas de inversión para sus promotores, las opciones de inversión para sus ahorradores, la protección del inversor y el cambio de promotor de un PEPP. La segunda fase es la de disposición y en ella se regulan el principio general de aplicación de las condiciones nacionales, las formas de las prestaciones y la planificación de la jubilación y el asesoramiento en materia de prestaciones.

Palabras clave: producto paneuropeo de pensiones individuales, PEPP, Reglamento (UE) 2019/1238, 


\begin{abstract}
This study analyzes Regulation (EU) 2019/1238 of the European Parliament and of the Council of 20 June 2019 on a pan-European Personal Pension Product (PEPP) in three sections: First, it set out the general aspects related to its form, its content and its temporary application. In the second section, the structure of the PEPP integrated by its objective aspects and by the subjects involved in its development is examined. The third section is devoted to analyzing the operation of the PEPP from two points of view: first, according to the planned actions (registration, distribution and supervision); and, second, according to the phases of the development of these PEPP that are two: the first phase is the accumulation phase and in it the investment rules for their promoters, the investment options for their savers, the protection of the investor and the change of promoter of a PEPP. The second phase is the decumulation phase and it regulates the general principle of application of national conditions, forms of benefits and retirement planning and advice on benefits.
\end{abstract}

Keywords: pan-European Personal Pension Product, PEPP, Regulation (EU) 2019/1238.

\title{
SUMARIO
}

I. PRESENTACIÓN: UNA EXPERIENCIA REGULATORIA INTERESANTE PARA IBEROAMÉRICA. II. ANTECEDENTES Y CONTEXTO: LA ARMONIZACIÓN DE LA ACTIVIDAD TRANSFRONTERIZA DE LOS FONDOS DE PENSIONES DE EMPLEO EN LA UNIÓN EUROPEA. III. ASPECTOS GENERALES DEL REGLAMENTO (UE) 2019/1238 QUE ESTABLECE EL PRODUCTO PANEUROPEO DE PENSIONES INDIVIDUALES(PEPP).IV.ESTRUCTURADELPRODUCTOPANEUROPEO DE PENSIONES INDIVIDUALES (PEPP). A) OBJETOS. B) SUJETOS. V. FUNCIONAMIENTO DEL PRODUCTO PANEUROPEO DE PENSIONES INDIVIDUALES (PEPP). A) LOS ASPECTOS DEL FUNCIONAMIENTO DE LOS PEPPSEGÚN LAS ACTUACIONES PREVISTAS EN EL REGLAMENTO (UE) 2019/1238. 1. Inscripción. 2. Distribución. 2.1. La aplicación del pasaporte comunitario. 2.2. Las normas de actuación de los promotores y distribuidores. 2.3. La transparencia precontractual mediante el documento de datos fundamentales del PEPP. 2.4. El asesoramiento de los promotores y distribuidores de PEPP. 3. Supervisión. 3.1. Supervisión en sentido estricto. 3.2. Régimen sancionador. B) LOS ASPECTOS DEL FUNCIONAMIENTO DE LOS PEPP SEGÚN LAS FASES DE SU DESARROLLO: FASE DE ACUMULACIÓN Y FASE DE DISPOSICIÓN. 1. La fase de acumulación. 1.1. Las normas de inversión para los promotores de PEPP. 1.2. Las opciones de inversión para los ahorradores en PEPP. 1.3. La protección del inversor. 1.4. El cambio de promotor de un PEPP. 2. La fase de disposición. 2.1. El principio general de aplicación de las condiciones nacionales - 2.2. Las formas de las prestaciones. 2.3. La planificación de la jubilación y el asesoramiento en materia de prestaciones. BIBLIOGRAFÍA. 


\section{PRESENTACIÓN: UNA EXPERIENCIA REGULATORIA INTERESANTE PARA IBEROAMÉRICA}

Comparezco en esta Revista Ibero-Latinoamericana de Seguros AIDA-CILA invitado por mi fraternal amigo, el Dr. Carlos Ignacio Jaramillo J. y -al amparo de su autoridad científica- ofrezco a los hermanos juristas de los países iberoamericanos la recentísima experiencia regulatoria del Producto Paneuropeo de Pensiones Individuales (PEPP), regulado por el Reglamento (UE) 2019/1238 desde el convencimiento de que puede resultar de utilidad para los países iberoamericanos por separado y para la comunidad jurídica, cultural y humana que constituyen.

Y mi convicción sobre la utilidad de la experiencia regulatoria del Producto Paneuropeo de Pensiones Individuales (PEPP) nace de dos constataciones elementales que son: por una parte, la afortunada extensión de la esperanza de vida en estos países que exige -como natural contrapunto- que los juristas iberoamericanos especializados en seguros y pensiones prevean los instrumentos jurídicos que garanticen los ingresos para una vida digna en esos "años de regalo vital"; $y$, por otra parte, la creciente circulación libre de personas entre los diferentes países iberoamericanos, circunstancia también afortunada que exige, asimismo, que los juristas iberoamericanos establezcan mecanismos para que esas personas que practican la feliz trashumancia puedan vivir tranquilos su vejez con planes de pensiones solventes y homologados en toda la comunidad de países iberoamericanos.

Pasamos, por lo anterior, a exponer en las páginas venideras las características técnico-jurídicas del Producto Paneuropeo de Pensiones Individuales (PEPP) para que los juristas iberoamericanos especializados en seguros y pensiones lectores de esta Revista puedan valorar su utilidad y aplicabilidad, desde su preciso conocimiento de la realidad jurídica tanto de sus respectivos países como de la comunidad de países iberoamericanos.

\section{ANTECEDENTES Y CONTEXTO: LA ARMONIZACIÓN DE LA ACTIVIDAD TRANSFRONTERIZA DE LOS FONDOS DE PENSIONES DE EMPLEO EN LA UNIÓN EUROPEA}

Debemos comenzar este estudio destacando que el grado de desarrollo de la regulación de la previsión social complementaria en la UE no es uniforme, sino que tiene "dos velocidades". En efecto, mientras que, por una parte, al acceso y el ejercicio de las actividades realizadas por los fondos de pensiones de empleo están armonizadas por la Directiva 
(UE) 2016/2341; por otra parte, se ha creado el régimen uniforme de un Producto Paneuropeo de Pensiones Individuales (PEPP) por el Reglamento (UE) 2019/1238 que analizamos en este estudio ${ }^{1}$.

Según decimos, la armonización de la actividad transfronteriza intracomunitaria de los fondos de pensiones de empleo en la UE se estableció, primero, por la Directiva 2003/41/CE, del Parlamento Europeo y del Consejo, de 3 de junio de 2003 relativa a las actividades y la supervisión de fondos de pensiones de empleo que establece normas relativas al acceso y al ejercicio de las actividades realizadas por aquellos tipos de fondos ${ }^{2}$. Esta Directiva fue derogada por la Directiva (UE) 2016/2341 del Parlamento Europeo y del Consejo, de 14 de diciembre de 2016, relativa a las actividades y la supervisión de los fondos de pensiones de empleo (FPE) (versión refundida) ${ }^{3}$ cuyo plazo de transposición venció el pasado 13 de enero de 2019 (art. 64), si bien su disposición derogatoria permite una suerte de pervivencia de las referencias a la anterior Directiva 2003/41/CE .

La Directiva 2003/41/CE fue traspuesta a nuestro Ordenamiento por la Ley 11/2006, de 16 de mayo, de adaptación de la legislación española al Régimen de Actividades Transfronterizas regulado en la Directiva 2003/41/CE del Parlamento Europeo y del Consejo, de 3 de junio de 2003, relativa a las actividades y supervisión de los fondos de pensiones de empleo mediante la adición de un nuevo Capítulo $\mathrm{X}$ al Texto Refundido de la Ley de regulación de los planes y fondos de pensiones, aprobado por el Real Decreto Legislativo 1/2002, de 29 de noviembre (LPFP) que regula la actividad transfronteriza de los fondos de pensio-

1 Sobre esta norma, puede verse nuestro reciente estudio "El producto paneuropeo de pensiones individuales (PEPP) Reglamento (UE) 2019/1238” (LA LEY 12565/2019) La Ley Unión Europea, № 74, 31 de Octubre de 2019, Doctrina pp.1-13. Wolters Kluwer.

2 V. el Informe de la Comisión sobre ciertos aspectos esenciales de la Directiva 2003/41/ CE relativa a las actividades y la supervisión de fondos de pensiones de empleo (Directiva FPE) [COM(2009) 203 final de 30.4.2009] y el Reglamento de Ejecución (UE) núm. 643/2014 de la Comisión, de 16 de junio de 2014, por el que se establecen normas técnicas de ejecución para la notificación de las disposiciones nacionales de carácter prudencial pertinentes en el ámbito de los planes de pensiones de empleo, de conformidad con la Directiva 2003/41/CE del Parlamento Europeo y del Consejo (DO L 177 de 17.6.2014, pp. 34-41).

$4 \quad$ DOUE 23.12.2016, pág. L 354/37 y ss.

$4 \quad$ En efecto, el art.65 dispone: "Queda derogada la Directiva 2003/41/CE, modificada por las Directivas que figuran en el anexo I, parte A, con efectos a partir del 13 de enero de 2019, sin perjuicio de las obligaciones de los Estados miembros relativas a los plazos de transposición al Derecho nacional y las fechas de aplicación de las Directivas que figuran en el anexo I, parte B. Las referencias a la Directiva 2003/41/CE derogada se entenderán hechas a la presente Directiva y se leerán con arreglo a la tabla de correspondencias que figura en el anexo II". 
nes de empleo ${ }^{5}$. Esta actividad se realizará mediante la integración de uno o varios planes de pensiones promovidos por empresas establecidas en Estados miembros distintos de aquel en el que está autorizado y registrado el fondo de pensiones en cuestión.

Aplicando estos principios al caso español, existen dos posibilidades de actividad transfronteriza de los fondos de pensiones de empleo ${ }^{6}$ : en primer lugar, un fondo de pensiones de empleo autorizado y registrado en España podrá integrar uno o varios planes de pensiones para los trabajadores promovidos por empresas establecidas en otros Estados miembros; $y$, en segundo lugar, un fondo de pensiones de empleo autorizado y registrado en otro Estado miembro podrá integrar uno o varios planes de pensiones para los trabajadores promovidos por empresas establecidas en España (art. 38.1 LPFP). De tal manera que podemos diferenciar dos tipos de movimientos:

a) Los «movimientos de salida» de los fondos de pensiones de empleo españoles hacia otros Estados comunitarios que se producirán cuando un fondo de pensiones de empleo autorizado y registrado en España integre uno o varios planes de pensiones para los trabajadores promovidos por empresas establecidas en otros Estados miembros (art. 38.1. párr. $1^{\circ}$ LPFP).

b) Los «movimientos de entrada» de los fondos de pensiones de empleo comunitarios en España que se producirán cuando un fondo de pensiones de empleo autorizado y registrado en otro Estado miembro de la UE integra uno o varios planes de pensiones para los trabajadores promovidos por empresas establecidas en España (art. 38.1.párr. 2. ${ }^{\circ}$ LPFP).

$5 \quad$ Los fondos de pensiones son patrimonios carentes de personalidad jurídica y afectos al cumplimiento de uno o varios planes de pensiones (art. 2 LPFP y art. 3 del Real Decreto $304 / 2004$, de 20 de febrero, por el que se aprueba el Reglamento de planes y fondos de pensiones, RPFP) y cuya titularidad corresponde a los partícipes y beneficiarios de los planes de pensiones integrados, conforme a la cuenta de posición que mantenga cada plan en el fondo (art. 8.4 LPFP y art. 17.1 RPFP). Según el tipo de planes de pensiones que integren, se pueden distinguir dos tipos de fondos: a) Fondos de pensiones de empleo, especializados en integrar planes del sistema de empleo (arts. 10.4 y 14.1.a) LPFP y arts. 3.3. a y 56.1.a RPFP). b) Fondos de pensiones personales, especializados en integrar planes del sistema asociado o individual (art. 14.1.b y c LPFP y arts. 3.3.b y 56.1.b RPFP). Cfr., por referencia al Derecho español, DUQUE DOMÍNGUEZ, J., «Notas delimitadoras y naturaleza jurídica de los fondos de pensiones», en SÁNCHEZ CALERO, F. (Dir.), «Régimen jurídico de los planes y fondos de pensiones», 2a ed., Madrid 1989, págs. 53 y ss.; LACASA GARCÍA, R., «Los Fondos de Pensiones», Madrid 1997, págs. 107 y ss. y nuestro estudio «La gestión de los fondos de pensiones: un análisis jurídico», RDBB 46, 1992, pp. 375 y ss.

6 V. nuestro “Derecho de Seguros y Fondos de Pensiones", Madrid 2014, pág.294 y ss. 


\section{ASPECTOS GENERALES DEL REGLAMENTO (UE) 2019/1238 QUE ESTABLECE EL PRODUCTO PANEU- ROPEO DE PENSIONES INDIVIDUALES (PEPP)}

En el DOUE de 25.7.2019 (p. L 198/1 y ss.) se ha publicado el Reglamento (UE) 2019/1238 del Parlamento Europeo y del Consejo, de 20 de junio de 2019, relativo a un producto paneuropeo de pensiones individuales (PEPP $)^{7}$. Lo primero que hay que destacar es que esta disposición comunitaria representa un salto cualitativo en la regulación de la previsión social complementaria en la UE porque, por una parte, utiliza un tipo de disposición unificadora (Reglamento) frente a la armonizadora previa (Directiva) y, por otro lado, cambia el ámbito material porque frente a los fondos de pensiones de empleo trata de los productos de pensiones individuales ${ }^{8}$.

Esta unificación y ampliación del ámbito material de aplicación hace que el Reglamento (UE) 2019/1238 este llamado a tener una enorme importancia para la seguridad social complementaria en Europa y, en particular, para la industria europea y española de las prensiones privadas.

En relación con esta última proyección financiera futura de estos PEPP, procede reparar en su doble dimensión: sustancial, de previsión social complementaria; e instrumental, de inversión financiera de los ingentes

7 V. la entrada de nuestro blog (ajtapia.com) de 21.03.2018 sobre "El Producto Paneuropeo de Pensiones Individuales (PEPP): Propuesta de Reglamento de la Comisión Europea y Dictamen del Comité Económico y Social Europeo" en la que nos referíamos a la Propuesta de Reglamento del Parlamento Europeo y del Consejo sobre un producto paneuropeo de pensiones individuales (PEPP) publicada el 29 de junio de 2017 por la Comisión Europea (ref. Comisión Europea, Bruselas, 29.6.2017, COM (2017) 343 final, 2017/0143 (COD), Texto pertinente a efectos del EEE, SWD (2017) 243 final, SWD (2017) 244 final) y al Dictamen del Comité Económico y Social Europeo sobre la propuesta de Reglamento del Parlamento Europeo y del Consejo sobre un producto paneuropeo de pensiones individuales (PEPP) aprobado en el Pleno de 19.10.2017 (D.O.U.E. 2.3.2018, C 81/139 y ss.).

8 A estos efectos, es pertinente recordar que existen tres modalidades de planes de pensiones en el Derecho español: a) Los planes de pensiones del sistema de empleo (art. $4 .^{\circ} 1 .^{\circ} \mathrm{a}$ LPFP y art. 2. ${ }^{\circ}$ 3.a RPFP), en los que actuará, como promotor, un empleador, con independencia de su naturaleza jurídica («cualquier empresa, sociedad, corporación o entidad») y, como partícipes, sus empleados; que podrán pertenecer al sector privado (trabajadores por cuenta ajena o asalariados vinculados al promotor por relación laboral, incluido el personal con relación laboral de carácter especial independientemente del régimen de la Seguridad Social aplicable) o al sector público (personal de las Administraciones y entes públicos promotores vinculado por relación de servicios dependiente regulada en normas estatutarias o administrativas) (art. 25.2 RPFP). b) Los planes de pensiones del sistema asociado (art. 4. 1.b LPFP y art. 2. 3.b RPFP), en los que actuará, como promotor, «cualquiera asociación o sindicato» y, como partícipes, sus «asociados, miembros o afiliados». c) Los planes de pensiones del sistema individual (art. 4. 1.c LPFP y art. 2. 3.c RPFP), en los que actuará, como promotor, «una entidad de carácter financiero» $y$, como partícipes, «cualesquiera personas físicas. 
recursos susceptibles de afectarse a estos PEPP. Es por ello por lo que los planes y fondos de pensiones son unos de los principales inversores institucionales "de segundo grado" porque, siendo su finalidad principal la previsión social complementaria; para desarrollarla necesitan invertir los recursos acumulados en nel mercado de capitales. Y es por ello por lo que el Reglamento (UE) 2019/1238 hace referencias constantes -en sus considerandos (11) y ss.- a la inserción de estos PEPP en el marco de la Unión de los Mercados de Capitales (UMC).

Dicho lo anterior, destacamos tres aspectos generales de este Reglamento (UE) 2019/1238:

a) Desde el punto de vista formal, resalta su extensión ya que el Reglamento está integrado por 90 considerandos y 74 artículos ordenados en 11 capítulos.

b) Desde el punto de vista sustancial, destaca que el objeto de este Reglamento consiste en establecer normas uniformes sobre la inscripción, producción, distribución y supervisión de los productos de pensiones individuales que se distribuyen en la Unión con la denominación «producto paneuropeo de pensiones individuales» o «PEPP». (art. 1). Siendo cierto el carácter unificador propio de este Reglamento (UE) 2019/1238, un análisis pormenorizado de su contenido pone de manifiesto un cierto carácter normativamente mixto porque, por una parte, "armoniza una serie de características fundamentales del PEPP que afectan a elementos clave, como la distribución, el contenido mínimo de los contratos, la estrategia de inversión, el cambio de promotor o la promoción y la portabilidad transfronterizas",; y, por otra parte, "establece normas uniformes sobre la inscripción, promoción, distribución y supervisión de PEPP"10.

c) Desde el punto de vista temporal, hay que destacar que la aplicación de este Reglamento -que es de por si obligatorio en todos sus elementos y directamente aplicable en cada Estado miembro- quedará postergada y condicionada a la publicación en el DOUE de una serie de actos delegados por parte de la Autoridad Europea de Seguros y Pensiones de Jubilación (AESPJ). Actos delegados que de detallan en el artículo 28, apartado 5, el artículo 30, apartado 2, el artículo 33, apartado 3, el artículo 36, apartado 2, el artículo 37, apartado 2, el artículo 45, apartado 3 , y en el artículo 46, apartado 3 (art. 74) $)^{11}$.

\footnotetext{
9 V. Considerando (21).

10 V. Considerando (23).

11 Sobre las facultades de desarrollo y ejecución de la AESPJ V. Considerandos (73) y ss.
} 


\section{ESTRUCTURA DEL PRODUCTO PANEUROPEO DE PENSIONES INDIVIDUALES (PEPP)}

\section{A) Objetos}

Las piezas centrales de la estructura del PEPP son:

1. La definición del «producto paneuropeo de pensiones individuales» o «PEPP» como "un producto de pensiones individuales de ahorro a largo plazo, que ofrece una empresa financiera apta con arreglo al artículo 6, apartado 1, en el marco de un contrato de PEPP, y que suscribe con un ahorrador en PEPP, o una asociación de ahorradores en PEPP independientes en nombre de sus miembros, de cara a su jubilación, con una posibilidad de rescate estrictamente limitada o nula e inscrito de conformidad con el presente Reglamento" (art. 2.3). A su vez, para reforzar la seguridad de los ahorradores se crea la variedad de PEPP básico que se define como "un producto seguro que represente la opción de inversión por defecto. Será diseñado por los promotores de PEPP sobre la base de una garantía sobre el capital que debe abonarse al inicio de la fase de disposición y durante dicha fase, cuando proceda, o una técnica de reducción del riesgo compatible con el objetivo de permitir que el ahorrador en PEPP recupere el capital". (arts. 2.27 y 45).

2. El establecimiento del contenido mínimo del contrato de PEPP que deberá incluir: "a) una descripción del PEPP básico a efectos del artículo 45, incluida información sobre la garantía del capital invertido o la estrategia de inversión dirigida a garantizar la protección del capital; b) una descripción de las opciones de inversión alternativas a que se refiere el artículo 42, apartado 2, cuando proceda; c) las condiciones relativas a la modificación de la opción de inversión a que se hace referencia en el artículo 44; d) en caso de que el PEPP ofrezca cobertura de riesgos biométricos, los detalles de tal cobertura, incluidas las circunstancias que la activarían; e) una descripción de las prestaciones de jubilación del PEPP, en especial las posibles formas de pago y el derecho a cambiar la forma de las prestaciones a que se hace referencia en el artículo 59; f) las condiciones relativas al servicio de portabilidad a que se hace referencia en los artículos 17 a 20, incluida la información sobre los Estados miembros para los que esté disponible una subcuenta; g) las condiciones relativas al servicio de cambio de promotor a que se hace referencia en los artículos 52 a 55; h) las categorías de costes y los costes agregados 
totales expresados en términos monetarios y de porcentaje, cuando proceda; i) las condiciones relativas a la fase de acumulación para la subcuenta correspondiente al Estado miembro de residencia del ahorrador en PEPP a que se hace referencia en el artículo 47; j) las condiciones relativas a la fase de disposición para la subcuenta correspondiente al Estado miembro de residencia del ahorrador en PEPP a que se hace referencia en el artículo 57; k) cuando proceda, las condiciones en las que las ventajas o los incentivos concedidos deben reembolsarse al Estado miembro de residencia del ahorrador en PEPP" (art. 4).

\section{B) Sujetos}

Los sujetos implicados operan en tres ámbitos:

1. Los clientes del PEPP que se definen como todo ahorrador en PEPP (toda persona física que haya celebrado un contrato de PEPP con un promotor de PEPP) futuro ahorrador en PEPP o beneficiario de PEPP (toda persona física receptora de las prestaciones del PEPP (art. 2.3, 6 y $7^{12}$ ).

2. Los intermediarios que operan en el entorno del PEPP que, a su vez, podrán ser:

a) Los promotores, definidos como "toda empresa financiera prevista en el artículo 6, apartado 1, autorizada para producir un PEPP y distribuir dicho PEPP" (art. 2.15),

b) Los depositarios, definidos como "toda entidad responsable de la custodia de los activos y la supervisión del cumplimiento de lo dispuesto en el reglamento del fondo y la legislación" (art. 2.26)

c) Los distribuidores definidos como "toda empresa financiera prevista en el artículo 6, apartado 1, autorizada a distribuir PEPP no producidos por ella, toda empresa de inversiones que ofrezca asesoramiento para la inversión o todo intermediario de seguros según la definición del artículo 2, apartado 1, punto 3, de la Directiva (UE) 2016/97 del Parlamento Europeo y del Consejo" (art. 2.16).

3. Las autoridades competentes de supervisión, definidas como las autoridades nacionales designadas por cada Estado miembro para supervisar a los promotores de PEPP o distribuidores de PEPP, según el caso,

12 Cfr., por referencia al Derecho español, BENITO OSMA, F., «Los partícipes y beneficiarios en la nueva regulación de los planes y fondos de pensiones», Madrid 2008. 
o para llevar a cabo las obligaciones previstas en el presente Reglamento (art. 2.18).

\section{FUNCIONAMIENTO DEL PRODUCTO PANEUROPEO DE PENSIONES INDIVIDUALES (PEPP)}

\section{A) LOS ASPECTOS DEL FUNCIONAMIENTO DE LOS PEPP SEGÚN LAS ACTUACIONES PREVISTAS EN EL REGLAMENTO (UE) 2019/1238}

El ciclo vital de los PEPP evoluciona a través de las siguientes actuaciones:

\section{Inscripción}

Un PEPP solo podrá ser producido y distribuido en la UE cuando haya sido inscrito en el registro público central gestionado por la AESPJ, inscripción que será válida para todos los Estados miembros de la UE y facultará al promotor del PEPP para ofrecerlo al distribuidor del PEPP para distribuirlo (art. 5). En este Registro público central de PEPPs -que gestionará la AESPJ, se publicará en formato electrónico y se mantendrá actualizado- se identificará cada PEPP inscrito mediante su número de inscripción, su promotor, las autoridades competentes del promotor, su fecha de inscripción, una lista completa de los Estados miembros en los que se ofrece el PEPP y una lista completa de los Estados miembros para los que el promotor de PEPP ofrece una subcuenta (art. 13).

\section{Distribución}

En la regulación de la distribución paneuropea de estos PEPP $\stackrel{13}{\text { pode- }}$ mos distinguir los siguientes aspectos:

\subsection{La aplicación del pasaporte comunitario}

Destaca, en primer lugar, el posible ejercicio de la libre prestación de servicios y la libertad de establecimiento por parte de los promotores

13 Cfr., por referencia al Derecho español, nuestro estudio sobre "La distribución de los planes de pensiones" en la obra colectiva sobre "La reforma del Derecho del seguro" (dirs. Bataller Grau, J. / Quintáns, R.), Ed. Aranzadi, 2015, pp. 515 a 544. 
de PEPP y los distribuidores de PEPP, quienes podrán ofrecer y distribuir, respectivamente, PEPP en el territorio de un Estado miembro de acogida en virtud de la libre prestación de servicios o la libertad de establecimiento, siempre que lo hagan con arreglo a las normas y procedimientos pertinentes establecidos por la normativa de la UE que les sea aplicable (art. 14 y ss.) ${ }^{14}$.

\subsection{Las normas de actuación de los promotores y distribuidores}

Cuando los promotores y distribuidores desarrollen actividades de distribución de PEPP, deberán actuar siempre con "honestidad, equidad y profesionalidad, en beneficio de los intereses de sus clientes de PEPP" $(\text { art. } 22 \text { y ss. })^{15}$.

\subsection{La transparencia precontractual mediante el do- cumento de datos fundamentales del PEPP}

Destaca la información precontractual que deben elaborar los promotores ya que, antes de proponer un PEPP a los ahorradores, el promotor deberá elaborar para dicho producto de PEPP un documento de datos fundamentales del PEPP que se ajuste a los requisitos del Reglamento y se publique en su sitio web. De este documento nos interesa resaltar los aspectos siguientes:

a) En cuanto se refiere a su contenido, entre los requisitos generales de este documento de datos fundamentales destacan la exigencia de que sea "preciso, imparcial, claro y no engañoso" y que aporte información fundamental y que sea "coherente con cualquier documento contractual de carácter vinculante, con las partes pertinentes de los documentos de la oferta y con las condiciones del PEPP”.

b) En lo que afecta a su formato, este documento de datos fundamentales del PEPP será un documento independiente, claramente separado del material comercial, al que no se remitirá. Si podrá remitirse a otros documentos, incluido, en su caso, un folleto de emisión, solamente si las remisiones guardan relación con la información que deba incluirse en el documento de datos fundamentales del PEPP en virtud del Reglamento.

14 V. Considerando (31).

15 Cfr., por referencia al Derecho español, nuestro esudio sobre los «Deberes y responsabilidades de los sujetos que intervienen en los planes y fondos de pensiones». RES 90, 1997, pp. 71 y ss. 
Cabe destacar, igualmente, que deberá elaborarse un documento de datos fundamentales independiente para el PEPP básico (art. 26 y ss.).

c) Nos interesa destacar el régimen especial de responsabilidad civil que puede derivar de este documento de datos fundamentales del PEPP desde dos puntos de vista: En cuanto al deudor eventual, el promotor del PEPP no incurrirá en responsabilidad civil sobre la base únicamente del documento de datos fundamentales del PEPP, incluida cualquier traducción del mismo, a no ser que sea engañoso, impreciso o incoherente con las partes pertinentes de la documentación contractual o precontractual jurídicamente vinculante o con los restantes requisitos legales. En lo que se refiere al eventual acreedor, un ahorrador en PEPP que demuestre haber sufrido una pérdida derivada de la confianza depositada en un documento de datos fundamentales en las circunstancias legales al celebrar un contrato de PEPP para el que se haya elaborado dicho documento, podrá reclamar daños y perjuicios por tal pérdida al promotor del PEPP de conformidad con el Derecho nacional (art. 31).

Por último, es importante dejar constancia de que este documento de datos fundamentales del PEPP debe sustituir y adaptar el documento de datos fundamentales relativo a los productos de inversión minorista vinculados y los productos de inversión basados en seguros con arreglo al Reglamento (UE) núm. 1286/2014 del Parlamento Europeo y del Consejo, de 26 de noviembre de 2014, sobre los documentos de datos fundamentales relativos a los productos de inversión minorista empaquetados y los productos de inversión basados en seguros ${ }^{16}$; de tal manera que este último no necesitaría facilitarse en el caso de los PEPP ya que debe elaborarse un documento de datos fundamentales independiente para el PEPP básico ${ }^{17}$.

\subsection{El asesoramiento de los promotores y distribuidores de PEPP}

Los promotores y distribuidores de PEPP deberán proporcionar a los clientes un asesoramiento tanto antes como durante la duración del contrato $^{18}$. En efecto:

16 DO L 352 de 9.12.2014, p. 1. V. nuestra noticia en la RDBB N. ${ }^{\circ} 148$ (2017) sobre "La Comunicación de la Comisión Europea de 7 de julio de 2017 de orientaciones en la aplicación de las normas sobre los documentos de datos fundamentales, pp. 337 a 341 .

17 A este documento de datos fundamentales del PEPP se refieren los Considerandos (38) y ss. de este Reglamento (UE) 2019/1238.

18 Es interesante recordar que, a los deberes de transparencia de las entidades financieras en la comercialización y gestión de los planes de pensiones del sistema individual se refiere la 
a) En primer lugar, antes de la celebración de un contrato de PEPP, el promotor del PEPP o distribuidor del PEPP "especificará, en función de la información solicitada y recibida del futuro ahorrador en PEPP, las exigencias relativas a la jubilación y las necesidades de dicho futuro ahorrador, incluida la posible necesidad de adquirir un producto que ofrezca una renta, y le facilitará información objetiva sobre el PEPP de forma comprensible para que pueda tomar una decisión informada" $y$ "todo contrato de PEPP que se proponga respetará las exigencias $y$ necesidades en materia de jubilación del ahorrador en el PEPP, teniendo en cuenta los derechos de pensión que dicho ahorrador haya devengado" (art. 34).

b) En segundo lugar, durante la duración del contrato, los promotores elaborarán un documento denominado "declaración de las prestaciones del PEPP" que será un "documento personalizado conciso, que facilitarán durante la fase de acumulación, con información relevante para cada ahorrador en PEPP, teniendo en cuenta la naturaleza especifica de los sistemas nacionales de pensiones y de toda normativa aplicable, incluido el Derecho nacional en materia social, laboral y tributaria" (art. 35 y ss. $)^{19}$.

\section{Supervisión}

Esta tercera fase de actuaciones sobre los PEPP abarcará los dos aspectos clásicos siguientes ${ }^{20}$ :

\subsection{Supervisión en sentido estricto}

Su supervisión en sentido estricto, ya que las autoridades competentes del promotor de PEPP supervisarán el cumplimiento del Reglamento de forma permanente y de conformidad con el régimen y las normas de supervisión sectoriales pertinentes; siendo también responsables de supervisar el cumplimiento de las obligaciones establecidas en el reglamento interno o en la escritura de constitución del promotor de PEPP y la adecuación de sus disposiciones y su organización a las tareas que

\footnotetext{
jurisprudencia de la Sala Primera de lo Civil del Tribunal Supremo, a la que nos referíamos en la entrada de nuestro blog (ajtapia.com) del pasado 6 de febrero de 2019 titulada "Transparencia exigible en los planes de pensiones individuales. La Sentencia del Tribunal Supremo n'.40/2019". 19 V. Considerando (43).

20 Cfr., por referencia al Derecho español, JIMÉNEZ-BLANCO, A., «Régimen de control administrativo (Inspección, infracciones, sanciones)», en MARTÍNEZ LAFUENTE, A. (Dir.) «Estudios sobre Planes y Fondos de Pensiones», Barcelona 1989, pp. 227 y ss
} 
deben cumplirse a la hora de ofrecer un PEPP. Además. la AESPJ y las autoridades competentes supervisarán los productos de pensiones individuales facilitados o distribuidos, a fin de comprobar que dichos productos solo son denominados «PEPP» o que se dé a entender que son un PEPP solo cuando estén inscritos en virtud del presente Reglamento (art. 61 y ss.).

\subsection{Régimen sancionador}

Su régimen sancionador porque, sin perjuicio de las facultades de supervisión de las autoridades competentes y del derecho de los Estados miembros a establecer e imponer sanciones penales; los Estados miembros deberán adoptar las normas sobre las sanciones administrativas y otras medidas adecuadas aplicables a las infracciones del Reglamento y adoptarán todas las medidas necesarias para garantizar su aplicación. Dichas sanciones administrativas y otras las otras medidas que puedan establecerse serán efectivas, proporcionadas y disuasorias (art. 67 y ss.).

B) LOS ASPECTOS DEL FUNCIONAMIENTO DE LOS PEPP SEGÚN LAS FASES DE SU DESARROLLO: FASE DE ACUMULACIÓN Y FASE DE DISPOSICIÓN

En segundo lugar, la regulación del ciclo vital de los PEPP que establece el Reglamento puede exponerse de forma complementaria con el criterio anterior, conforme a la evolución en dos fases esenciales que son:

\section{La fase de acumulación}

Esta fase podemos destacar los siguientes aspectos:

\subsection{Las normas de inversión para los promotores de PEPP}

Estas normas de inversión deberán respetar, en general, la «regla de la persona prudente»y, en particular, los siguientes criterios: " $a$ ) los activos se invertirán defendiendo al máximo los intereses a largo plazo de los ahorradores en PEPP en su conjunto; en caso de posible conflicto de intereses, el promotor del PEPP o la entidad que gestione su cartera velará por que la inversión se realice defendiendo únicamente el interés de los 
ahorradores en PEPP; b) en virtud del principio de prudencia, los promotores de PEPP tendrán en cuenta los posibles efectos a largo plazo de las decisiones de inversión sobre factores $A S G$ y los riesgos relacionados con las mismas; c) los activos se invertirán de manera que se vele por la seguridad, calidad, liquidez y rentabilidad de la totalidad de la cartera; d) los activos se invertirán mayoritariamente en mercados regulados; las inversiones en activos no admitidos a negociación en un mercado financiero regulado se mantendrán en todo caso en niveles prudentes; e) la inversión en instrumentos derivados será posible en la medida en que dichos instrumentos contribuyan a la reducción del riesgo de inversión o faciliten la gestión eficaz de la cartera; estos instrumentos se evaluarán de manera prudente, teniendo en cuenta el activo subyacente, e incluirse en la evaluación de los activos del promotor de PEPP; los promotores de PEPP también evitarán la excesiva exposición al riesgo en relación con una única contraparte y con otras operaciones con derivados; f) los activos estarán suficientemente diversificados, de forma que se evite la dependencia excesiva respecto de un determinado activo, emisor o grupo de empresas y las acumulaciones de riesgo en el conjunto de la cartera; las inversiones en activos emitidos por el mismo emisor o por emisores que pertenezcan al mismo grupo no expondrán al promotor de PEPP a un riesgo de concentración excesivo; g) los activos no se invertirán en países ni territorios no cooperadores a efectos fiscales indicados en las conclusiones aplicables del Consejo relativas a la lista de países y territorios no cooperadores a efectos fiscales, ni en terceros paises de alto riesgo con deficiencias estratégicas indicados en el Reglamento Delegado de la Comisión aplicable adoptado sobre la base del artículo 9 de la Directiva (UE) 2015/849; h) el promotor de PEPP no se expondrá a sí mismo ni expondrá a los activos correspondientes al PEPP a riesgos provocados por un apalancamiento excesivo y una transformación de vencimientos excesiva" (art. 41).

\subsection{Las opciones de inversión para los ahorradores en PEPP}

Los promotores pueden ofrecer a los ahorradores un máximo de 6 opciones de inversión que incluirán el PEPP básico, podrán incluir opciones de inversión alternativas y se diseñarán siguiendo una garantía o técnica de reducción del riesgo, de tal modo que se garantice una protección suficiente a los ahorradores en PEPP; quedando la provisión de garantías sujeta al Derecho sectorial correspondiente aplicable al promotor de PEPP (art. 42) 


\subsection{La protección del inversor}

Esta protección del inversor en el PEPP se articula a través de los mecanismos siguientes:

a) Primero, la designación por los promotores de un depositario para la custodia de los activos en relación con la actividad de oferta de PEPP y las obligaciones de vigilancia, en cuanto a al nombramiento de este depositario y al desempeño de sus funciones en relación con la custodia de activos y la responsabilidad del depositario, así como las obligaciones de vigilancia del depositario, se aplicará el capítulo IV de la Directiva 2009/65/CE (art. 48).

b) En segundo lugar, la cobertura de riesgos biométricos ya que los promotores de PEPP podrán ofrecer PEPP con una opción que garantice la cobertura de riesgos biométricos (art. 49).

c) En tercer lugar un sistema de resolución de reclamaciones, ya que los promotores de PEPP y distribuidores de PEPP implantarán y aplicarán procedimientos adecuados y eficaces para resolver las reclamaciones presentadas por los clientes de PEPP en relación con sus derechos y obligaciones en virtud del Reglamento (art. 50).

d) En cuarto y último lugar, un sistema de Resolución extrajudicial de litigios (RAL) porque para la resolución de litigios entre los clientes de PEPP y los promotores o distribuidores de estos productos en relación con los derechos y obligaciones que emanan de lo dispuesto en el Reglamento; se establecerán procedimientos de RAL adecuados, independientes, imparciales, transparentes y eficaces, conforme a la Directiva 2013/11/UE del Parlamento Europeo y el Consejo; valiéndose, en su caso, de organismos competentes ya existentes (art. 51) ${ }^{21}$.

\subsection{El cambio de promotor de un PEPP}

Los promotores de PEPP prestarán un servicio de cambio de promotor por el que se transfieran, a petición del ahorrador en el PEPP, los importes correspondientes o, en su caso, los activos en especie de una cuenta de PEPP mantenida por el promotor de PEPP transmisor a una nueva cuenta de PEPP con las mismas subcuentas abierta en el promotor de PEPP receptor, con el cierre de la antigua cuenta de PEPP. Ceben desta-

21 V. Considerandos (60) y (61). 
car dos disposiciones que inciden en las posiciones del promotor y del ahorrador, respectivamente (art. 52) ${ }^{22}$ :

a) En cuanto al promotor de PEPP transmisor transferirá al promotor de PEPP receptor toda la información relacionada con todas las subcuentas de la antigua cuenta de PEPP, incluidos los requisitos de información. El promotor de PEPP receptor registrará dicha información en las subcuentas correspondientes.

b) En cuanto al ahorrador en PEPP, podrá solicitar el cambio de promotor a un promotor de PEPP establecido en el mismo Estado miembro (cambio nacional) o a un Estado miembro diferente (cambio transfronterizo). El ahorrador en PEPP podrá ejercer el derecho a cambiar de promotor durante las fases de acumulación y de disposición del PEPP.

\section{La fase de disposición}

En esta fase de disposición destaca la regulación de los siguientes aspectos:

\subsection{El principio general de aplicación de las condiciones nacionales}

Serán los Estados miembros quienes establezcan las condiciones relativas a la fase de disposición y las prestaciones de las subcuentas nacionales, salvo las que se especifiquen en el Reglamento. Añadiéndose que tales condiciones podrán incluir, en particular, la fijación de la edad mínima para el comienzo de la fase de disposición, de un plazo máximo antes de alcanzar la edad de jubilación para suscribir un PEPP, así como las condiciones de reembolso antes de la edad mínima para el comienzo de la fase de disposición, en particular en caso de dificultades especiales (art. 57).

\subsection{Las formas de las prestaciones}

Los promotores de PEPP deben poner a disposición de los ahorradores en PEPP una o más de las siguientes formas de prestaciones: renta; cantidad fija única; retiradas; o combinaciones de las formas anteriores. Serán los ahorradores en PEPP quienes elijan la forma de las prestaciones en la fase de disposición al celebrar el contrato de PEPP y al solicitar la apertura de una nueva subcuenta., pudiendo modificar tales formas (arts. 58 y 59).

22 V. Considerandos (62) y ss. 


\subsection{La planificación de la jubilación y el asesoramiento en materia de prestaciones}

Por último, nos parece particularmente novedosa e interesante la regulación de la planificación de la jubilación y el asesoramiento en materia de prestaciones ya que el Reglamento -en su art. 60- dispone que, en el caso del PEPP básico, al inicio de la fase de disposición, el promotor deberá ofrecer al ahorrador planificación de la jubilación individual en lo que concierne al uso sostenible del capital acumulado en las subcuentas del PEPP, teniendo en cuenta, en todo caso, una serie de factores como son el valor del capital acumulado en las subcuentas del PEPP, el importe total de los demás derechos de jubilación devengados y as exigencias y necesidades relacionadas con la jubilación a largo plazo del ahorrador. Esta planificación de la jubilación incluirá una recomendación individual al ahorrador sobre su forma óptima de prestaciones, a menos que solo se ofrezca una única forma de prestaciones.

\section{BIBLIOGRAFÍA}

BENITO OSMA, F. (2008). «Los partícipes y beneficiarios en la nueva regulación de los planes y fondos de pensiones», Madrid.

DUQUE DOMÍNGUEZ, J. (1989). «Notas delimitadoras y naturaleza jurídica de los fondos de pensiones», en Sánchez Calero, F. (Dir.), «Régimen jurídico de los planes y fondos de pensiones», $2^{\text {a }}$ ed., Madrid, pp. 53 y ss.

JIMÉNEZ-BLANCO, A. (1989). «Régimen de control administrativo (Inspección, infracciones, sanciones)», en Martínez Lafuente, A. (Dir.) «Estudios sobre Planes y Fondos de Pensiones», Barcelona, pp. 227 y ss.

LACASA GARCÍA, R. (1997). «Los Fondos de Pensiones», Madrid, pp. 107 y ss.

TAPIA HERMIDA, A.J. (1992). «La gestión de los fondos de pensiones: un análisis jurídico», Revista de Derecho Bancario y Bursátil núm. 46, pp. 375 y ss.

Id. (1997). «Deberes y responsabilidades de los sujetos que intervienen en los planes y fondos de pensiones». Revista Española de Seguros núm. 90, pp. 71 y ss.

Id. (2015). La distribución de los planes de pensiones" en "La reforma del Derecho del seguro” (Dirs. Bataller Grau, J. / Quintáns, R.), Ed. Aranzadi, pp. 515 a 544.

Id. (2014). "Derecho de Seguros y Fondos de Pensiones”, Ed. Iustel, Madrid, pp. 294 y ss.

Id. (2017). "La Comunicación de la Comisión Europea de 7 de julio de 2017 de orientaciones en la aplicación de las normas sobre los documentos de datos fundamentales", Revista de Derecho Bancario y Bursátil núm. 148, pp. 337 a 341.

Id. (2019). "El producto paneuropeo de pensiones individuales (PEPP) Reglamento (UE) 2019/1238” (LA LEY 12565/2019) La Ley Unión Europea, № 74, 31 de Octubre. Doctrina pp. 1-13. Wolters Kluwer. 
